\section{Full-thickness laparoendoscopic stapled excision of colonic lesion in a porcine ex vivo model}
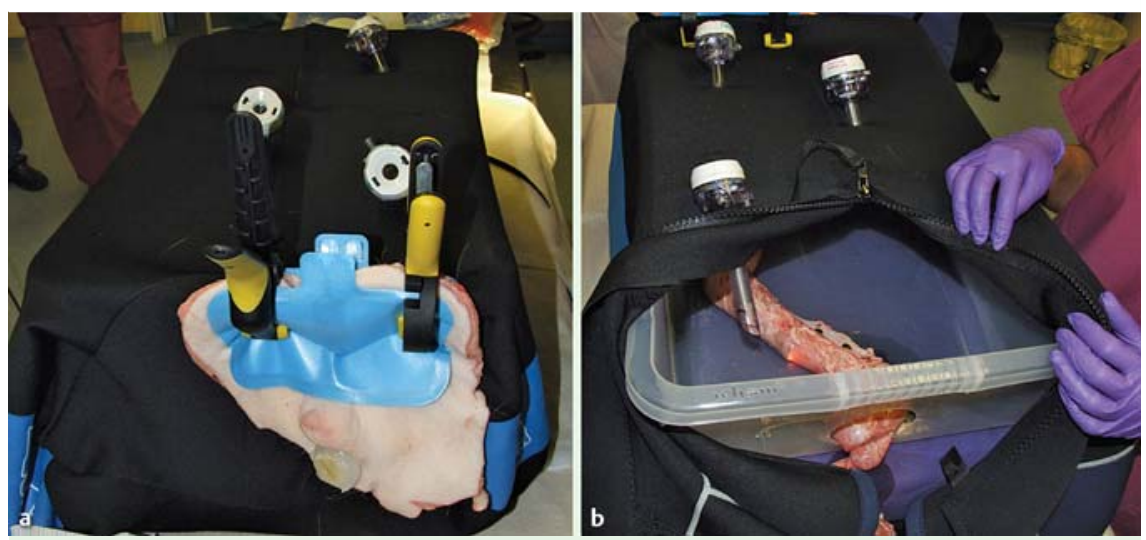

Fig. 1 a, b Handmade laparoscopic training box containing a colonic specimen.

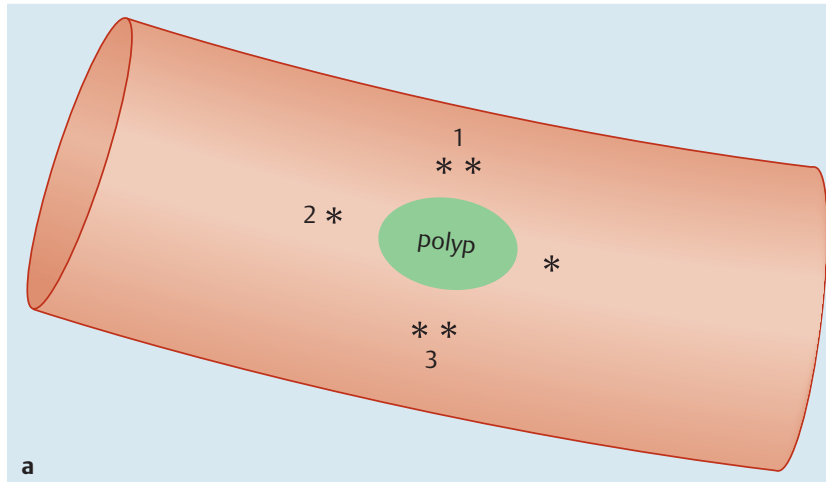

a

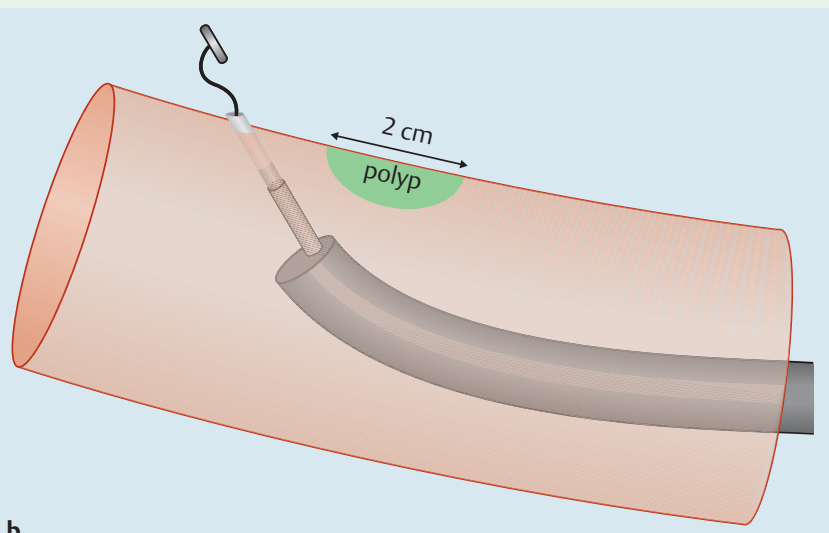

b

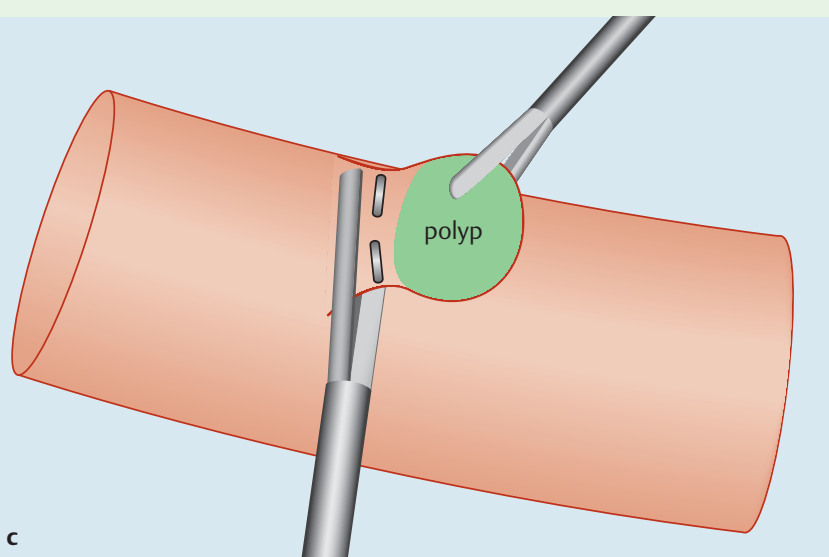

Fig. 2 a Overview of brace bar placement at 3,9 , and 12 and 6 o'clock positions. b Endoscopic placement of brace bars $1 \mathrm{~cm}$ away from the edge of the lesion. c Cinched brace bars evert the area of the bowel containing the simulated lesion. The tracted using a laparoscopic grasper and the specimen excised with a laparoscopic linear stapler. This results in a simultaneous closure of the colon and the excised specimen. Adequate clearance margin is achieved by placing the stapler below the brace bars. everted segment is re-
The introduction of the National Bowel Cancer Screening Programme in the United Kingdom has resulted in an increasing number of patients requiring hemicolectomy for endoscopically unresectable benign colonic polyps [1,2]. Laparoscopic hemicolectomy with en bloc mesenteric resection is a morbid intervention as death (2\%), anastomotic leakage (7\%), and other complications (34-46\%) can occur [3]. These patients derive no additional benefit from removal of the mesentery and a new, less invasive treatment option is required. We report a modified version of the previously published Full-thickness Laparoendoscopic EXcision (FLEX) technique [4].

A porcine colon specimen was placed in a handmade laparoscopic training box ( Fig.1). A 2-3-cm simulated colonic polyp was made by submucosal injection of India ink. Three pairs of brace bars (Prototype BraceBar system; Olympus, Tokyo, Japan) ( Fig.2) were placed endoscopically, $1 \mathrm{~cm}$ away from the edge of the polyp, delineating a circumferential clearance margin. Cinching of the brace bars resulted in full-thickness eversion of the colonic wall containing the simulated lesion. The specimen was excised with a laparoscopic linear stapler (ENDOPATH ETS-45; Ethicon Endo-surgery, Cincinnati, Ohio, USA) placed below the brace bars. The average procedure time (from placement of brace bars to specimen excision) was 46 minutes, resulting in four fullthickness colonic specimens, median diameter of $4.8 \mathrm{~cm}(3.7-6.3 \mathrm{~cm})$. All specimens contained three pairs of brace bars with clear resection margins ( $\bullet$ Fig. 3 and - Fig.4). Endoscopic examination demonstrated widely patent lumen without evidence of stenosis at excision sites.

This proof-of-concept study demonstrates the feasibility of achieving full-thickness colonic specimens exceeding $6 \mathrm{~cm}$ in diameter. Accurate endoscopic placement of the brace bars ensures completeness of excision while laparoscopic overview minimizes the risk of collateral damage. Importantly, lesion resection with simultaneous closure of the defect is achieved effectively and simply by use of a standard linear stapling device. The eversion FLEX is safe for in vivo assessment as a potential alternative to hemicolectomy in selected patients. 

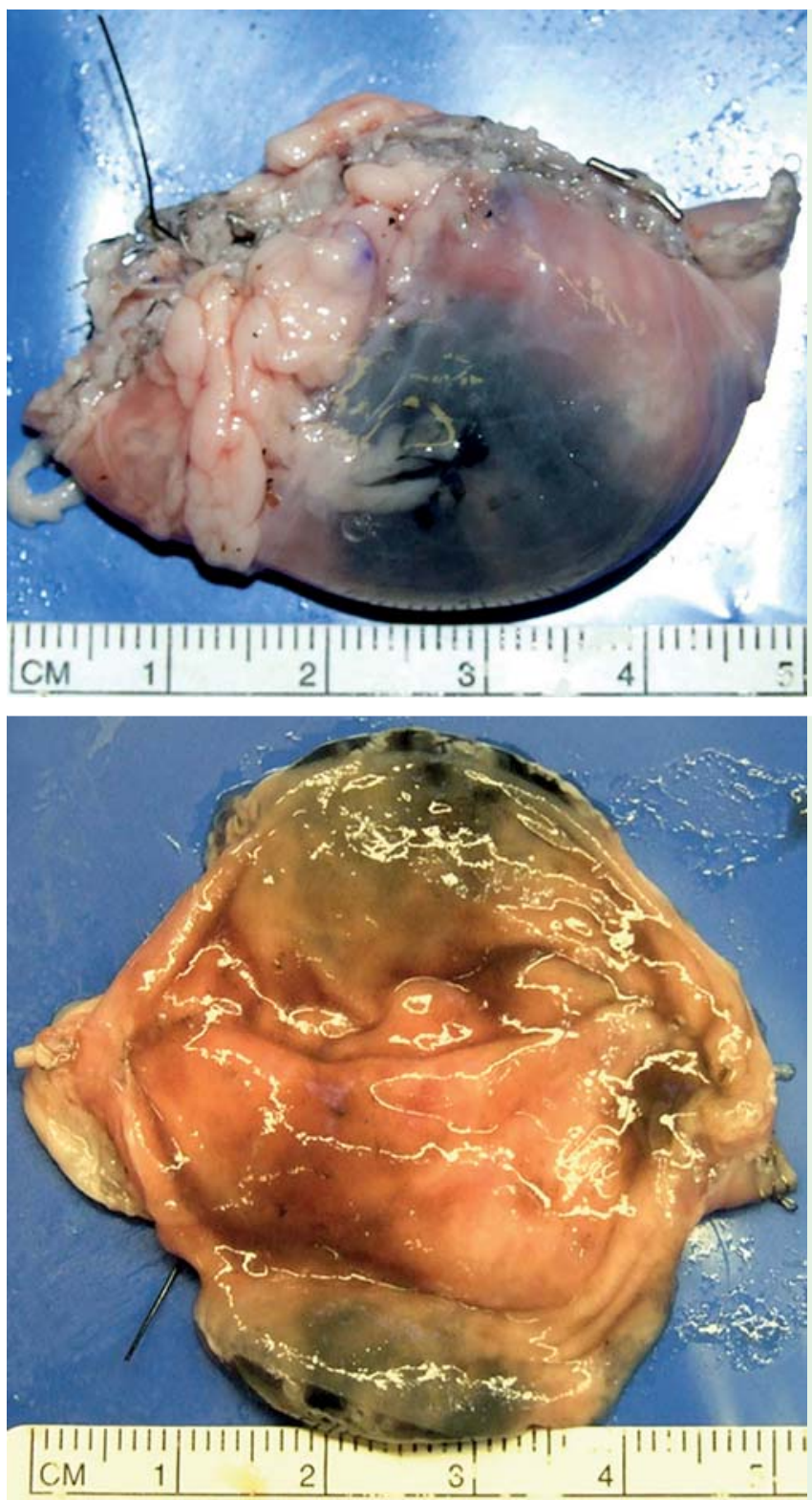

\section{Acknowledgments}

$\nabla$

Olympus Keymed and Ethicon Endo-surgery provided technical support. We are grateful for the support of Ms Cathy Grey, Research Theatre Manager, and Mr Aaron Southgate, Northwick Park Institute for Medical Research, London, United King-
Fig. 3 Stapled colonic specimen avoiding the risk of peritoneal contamination with potentially malignant cells.

Fig. 4 Excised colonic specimen.

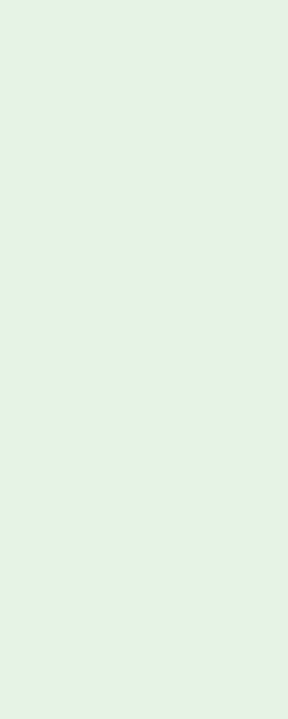

\section{A. Brigic ${ }^{1,2}$, A. Southgate ${ }^{3}$, P. D. Sibbons ${ }^{3}$, S. K. Clark ${ }^{1}$, C. Fraser ${ }^{2}$, R. H. Kennedy ${ }^{1}$}

${ }^{1}$ Department of Surgery, St. Mark's Hospital and Academic Institute, Watford Road, London, United Kingdom

2 Wolfson Unit for Endoscopy, St. Mark's Hospital and Academic Institute, Watford Road, London, United Kingdom

${ }^{3}$ Northwick Park Biomedical Institute, Biomedicine, Watford Road, London, United Kingdom

\section{References}

1 Lee TJ, Pascall G, Wood T et al. Colonic polyps are different in the UK bowel cancer screening programme population compared to the symptomatic population. Gastrointest Endosc 2009; 69: AB290 -AB291

2 Harrow P, Nayagam S, Stafford $N$ et al. A comparison of incidence of colorectal cancer and polyps in bowel cancer screening programme patients with symptomatic patients referred under 2 week wait in a demographically matched population. Gut 2011; 60: A114

3 Vlug MS, Wind J, Hollmann MW et al. Laparoscopy in combination with fast track multimodal management is the best perioperative strategy in patients undergoing colonic surgery. Ann Surg 2011; 254: 868-875

4 Kennedy RH, Cahill RA, Sibbons $P$ et al. The "FLEX" procedure: a new technique for fullthickness laparo-endoscopic excision in the colon. Endoscopy 2011; 43: 223-229

\section{Bibliography}

Dol http://dx.doi.org/

10.1055/s-0032-1326462

Endoscopy 2013; 45: E167-E168

(c) Georg Thieme Verlag KG

Stuttgart · New York

ISSN 0013-726X

\section{Corresponding author}

\section{R. Kennedy}

Department of Surgery

St. Mark's Hospital and Academic Institute Watford Road

London, HA1 3U]

UK

Fax: +44 2082354108

\section{Competing interests: None}

